\title{
The Design of an Android-Based Integrated Islamic Boarding School Information System as a Solution to the Impact of Covid-19
}

Perancangan Sistem Informasi Pondok Pesantren Terintegrasi Berbasis Android Sebagai Solusi dari Dampak Covid-19

\author{
Syauqie Muhammad Marier'1, Anis Susila Abadi² \\ ${ }^{1,2}$ Informatika, Universitas Nahdlatul Ulama Yogyakarta, Indonesia \\ 1*syauqie.mm@unu-jogja.ac.id, 2anis.abadi@unu-jogja.ac.id \\ *: Penulis korenspondensi (corresponding author)
}

\section{Informasi Artikel}

Received: July 2021

Revised: August 2021

Accepted: September 2021

Published: October 2021
Keywords:integration system; islamic boarding school; REST API

Kata kunci: sistem terintegrasi; pondok pesantren; REST API

\begin{abstract}
Purpose: This study aims so that all information that is spread through various information systems in Islamic boarding schools can be known through an integrated system

Design/methodology/approach: The method of developing the system using the prototype method

Findings/result: Android-based integrated information system

Originality/value/state of the art: System integration in Islamic boarding schools that is carried out is the integration process of various systems that previously existed
\end{abstract}

\begin{abstract}
Abstrak
Tujuan: Penelitian ini bertujuan agar semua informasi yang tersebar melalui berbagai sistem informasi di pondok pesantren dapat diketahui melaui satu sistem yang terintegrasi

Perancangan/metode/pendekatan: Metode pengembangan sistemnya menggunakan metode prototype

Hasil: Sistem informasi terintegrasi berbasis android Keaslian/ state of the art: integrasi sistem di pondok pesantren yang dilakukan adalah proses integrasi dari berbagai sistem yang sebelumnya sudah ada.
\end{abstract}




\section{Pendahuluan}

Pada masa pandemi Covid-19 saat ini, pemanfaatan teknologi yang dulunya terbatas pada sektor tertentu, sekarang hampir semua sektor dituntut untuk menggunakan teknologi pada aktifitasnya. Sektor pemerintahan, ekonomi, politik, budaya maupun pendidikan [1]. Semua aktifitas yang dulunya bersifat offline diarahkan menjadi online, untuk menghindari perkumpulan masa. Tak terkecuali pendidikan di pondok pesantren [2], [3].

Munculnya beberapa cluster Covid-19 di pondok pesantren, berdampak pada pemulangan santri ke rumah masing-masing. Dilanjut dengan berbagai kebijakan pemerintah seperti Pembatasan Sosial Berskala Besar (PSBB) sampai Pemberlakuan Pembatasan Kegiatan Masyarakat (PPKM). Kondisi demikian memberikan dampak yang berarti terhadap kegiatan di pondok pesantren. Akibat yang dirasakan santri adalah kesulitan dalam pembelajaran dan mendapatkan informasi terbaru lainnya. Begitu pula bagi pondok pesantren, kesulitan yang dihadapi adalah bagiaman memantau dan memastikan perkembangan pembelajaran santri berjalan dengan baik.

Implementaasi teknologi yang diterpkan di pondok pesantren tentunya berbeda-beda sesuai dengan kondisi tiap pondok. Ada yang menggunakan teknologi messanger seperti whatsapp [4], ada yang menggunakan google classroom, website sekolah/pondok dan ada yang menggunakan sistem/aplikasi lainnya [5]. Berikut berbagai sistem yang telah peneliti lain lakukan di pondok pesantren. Sistem informasi administrasi santri pondok pesantren sumur Bandung [6] dan administrasi pembayaran berbasis web dan sms gateway [7]. Sistem akademik berbasis web pada pesantren tahfidz adh Dhuhaa Bulak Santri [8]. Sistem informasi manajemen santri di pondok pesantren al ishlah kota Kediri menerapkan integrasi sistem keuangan dan perekapan data pengurus berbasis web menggunakan PHP [9]. Sistem informasi manajemen kegiatan santri pondok pesantren berbasis web menggunakan [10]. Sistem monitoring hafalan Qur'an [4], [11].

Berdasarkan pengamatan penulis pada referensi tersebut, sistem yang dirancang masih bersifat stand-alone dan bersifat parsial. Adanpun penelitian dengan judul terintegrasi, bukan menunjukkan integrasi antar sistem yang ada, tetapi pembuatan modul modul/menu pada sistem informasi. Belum terintegarsinya berbagai sistem, membuat santri maupun orang tua santri terkadang kebingungan dalam menghimpun informasi. Kebingungan dikarenakan banyaknya sistem yang ada, sehingga menjadikan sering lupa. Sebagai contoh, informasi terkait tugas yang diberikan oleh guru/ustadz disampaikan melalui berbagai aplikasi [2], seperti whatsapp, pengumpulan tugas melalui classroom, informasi keuangan menunggu pemberitahuan melalui pesan whatsapp oleh pengurus dan informasi mengaji Qur'an melalui sistem tersendiri.

Penelitian ini akan menjawab beberapa pertanyaan penelitian, yaitu bagaimana merancang agar semua informasi yang tersebar melalui berbagai sistem informasi, dapat diketahui melaui satu sistem yang terintegrasi. Kedua, sistem dirancang berbasis android agar dapat diakses dengan mudah. Pendekatan integrasi yang diusulkan menggunakan web service metode REST (Representational State Transfer). REST dipilih karena banyak digunakan di Indonesia [13] dan sering dipakai untuk pengembangan aplikasi berbasis android [14]. Arsitektur yang dirancang menggunakan API (Application Programming Interface) dan format data JSON [15]. REST API didefinisikan sebagai arsitektur yang dirancang pada layanan web yang berfokus pada resources sistem seperti transfer \& request data menggunakan protocol HTTP [16]. 


\section{Metode/Perancangan}

\subsection{Pengumpulan Data}

Pada tahap pengumpulan data, metode yang dilakukan adalah wawancara dan studi pustaka. Wawancara pada penelitian ini dilakukan bersama pengasuh pondok pesantren Darussalam Subah. Sedangkan studi pustaka dilakukan dengan melakukan pencarian pada google scholar dengan kata kunci sistem pondok pesantren.

\subsection{Metode Integrasi}

Tahap integrasi pada penelitian ini menggunakan web service dengan metode REST. Ilustrasi rancangan arsitektur integrasi sistem di pondok pesanten menggunakan REST API sebagaimana pada Gambar 1 berikut.

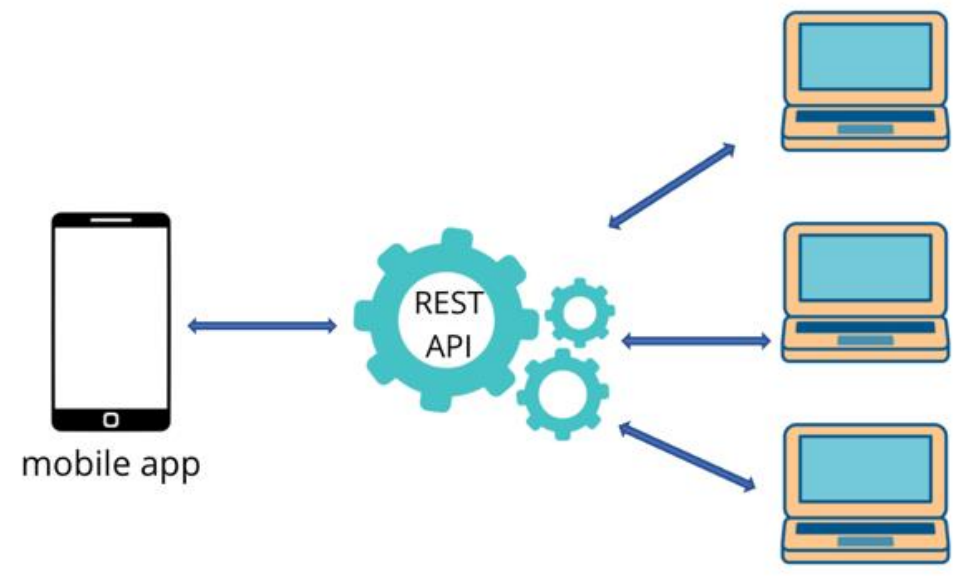

Gambar 1. Arsitektur REST API pada Percancnagan sistem integrasi pondok pesantren

Metode perancangan REST API dalam integrasi sistem terdiri dari enap tahap yaitu identifikasi, memahami ekosistem organisasi, mengidentifikasi kemungkinan integrasi, identifikasi kemampuan integrasi yang diperlukan, desain API dan Implementasi [17].

\subsection{Metode Pengembangan Sistem}

Metode pengembangan aplikasi berbasis android yang digunakan pada penelitian ini adalah dengan menggunakan metode prototype. Metode prototype sebagaimana yang digambarkan pada Gambar 2, dijelaskan oleh Pressman [18] dimulai dengan communication. Pada tahap ini, kegiatan yang dilakukan adalah bertemu dengan stakeholder untuk menentukan tujuan keseluruhan perangkat lunak dan mengidentifikasi requirement sistem. 


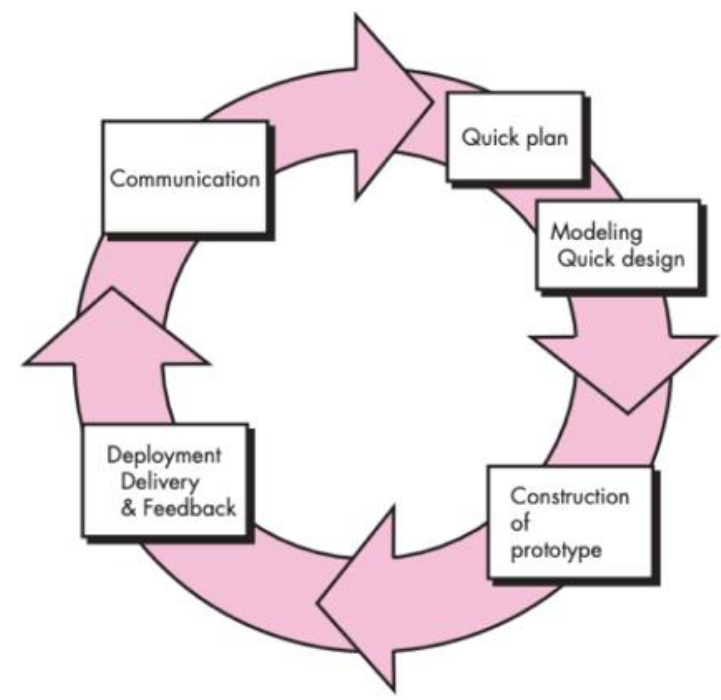

Gambar 2. Metode Prototype

\subsubsection{Communication}

Developer berkomunikasi dengan stakeholder untuk menentukan format keseluruhan perangkat lunak, mendefinisikan requirement, dan garis besar dari sistem yang akan dikembangkan. Pada tahap ini datanya dikumpulkan dengan metode wawancara dan observasi. Wawancara dan observasi dilakukan guna mendapatkan jawaban empat tahap awal dari enam tahap pada perancangan REST API. Keempat tahap tersebut identifikasi, memahami ekosistem organisasi, mengidentifikasi kemungkinan integrasi, identifikasi kemampuan integrasi yang diperlukan.

Hasil pengumpulan data kemudian dianalisis dan didefinisikan requirement system sebagai dasar informasi tentang desain sistem yang akan dibangun. Tahapan requirement system dilakukan menggunakan model DFD (Data Flow Diagram). DFD merupakan penggambaran rancangan sistem yang dimulai dengan pembuatan diagram konteks dan berfokus pada aliran data untuk kebutuhan analisis masukan, proses dan luaran pada sistem [19].

Sebagaimana yang disebutkan oleh sofitri, komponen yang harus digambarkan pada DFD adalah terminator, data store, proses dan alur data. Terminator adalah gambaran untuk entitas eksternal. Data store adalah gambaran simpanan data, bisa berupa file ataupun basis data. Proses adalah gambaran aktivitas sistem yang merubah masukan menjadi luaran. Alur data adalah gambaran arus data pada sistem. Gambaran komponen DFD digambarakan pada pada Gambar 3 berikut.

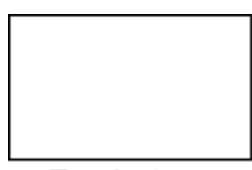

Terminator

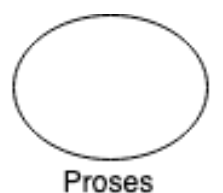

Proses

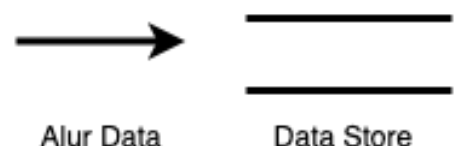

Data Store

Gambar 3. Komponen DFD

\subsubsection{Quick Plan and Modeling Quick Design}

Pada tahap ini dilakukan perancangan desain model secara cepat. Desain yang dihasilkan berfokus pada representasi dari aspek-aspek perangkat lunak misalnya, tata letak antarmuka atau tampilan luaran sistem. Konsep yang digunakan adalah konsep user interface design. 
Antarmuka didesain agar interaksi antara end user dan sistem menjadi efektif dan sesuai dengan tahapan sebelumnya yaitu requirement system.

User interface design menurut [20] harus dikembangan dengan prinsip Learnability, User familiarity, Consistency, Minimal surprise, Recoverability, User guidance dan User diversity. Learnability, sistem harus mudah dipelajari sehingga pengguna dapat dengan cepat menggunakan sistem. User familiarity, sistem harus menggunakan istilah yang sering digunakan oleh pengguna. Consistency, sistem harus memiliki konsistensi. Minimal surprise, perilaku sistem tidak mengejutkan pengguna. Recoverability, sistem menyediakan kemungkinan pengguna untuk recover dari eror. User guidance, sistem harus memberikan umpan balik dan memberikan bantuan apabila terjadi eror. User diversity, sistem harus mendukung interaksi dari berbagai tipe pengguna.

\subsubsection{Construction of Prototype}

Tahap pembuatan prototype dimulai berdasarkan spesifikasi perangkat yang ditentukan sebelumnya sesuai dengan kebutuhan pengguna. Pada tahap ini dilakukan coding dan debugging yang melibatkan perencanaan, desain, pengujian unit, pengujian integrasi dan lainnya [20]. Sistem dikembangkan menggunakan framework flutter.

\subsubsection{Development Delivery Feedback}

Pada tahap ini, prototype diserahkan kepada stakeholder dan akan diuji oleh pengguna. Kemudian dilakukan evaluasi kembali terhadap kekurangan kebutuhan pengguna untuk memperbaiki prototype yang ada. Tahap ini memverifikasi tingkah laku dari sistem dengan memberikan contoh kasus uji coba. Uji coba berupa memberikan masukan dan mengamati reaksi yang muncul, apakah sesuai dengan yang dihaparkan atau tidak.

\section{Hasil dan Pembahasan}

\subsection{Hasil Pengumpulan Data}

Penelitian dilakukan dengan melakukan wawancara pada salah satu pengasuh di pondok pesantren Darussalam Subah kabupaten Batang Jawa Tengah. Wawancara dan observasi bertujuan untuk mengidentifikasi dan memahami ekosistem pondok. Didapatkan gambaran umum existing sistem yang ada pada pondok tersebut yaitu, website pondok, website sekolah, sistem PPDB (Penerimaan Peserta Didik Baru) dan sistem akademik santri. Sistem tersebut didapatkan dengan membuat sendiri dan mendownload software yang ada di internet. Keempat sistem yang ada, belum saling terintegrasi.

Keempat sistem yang ada diidentifikasi kemungkinannya untuk diintegrasikan. Hasilnya memungkinan untuk dilakukan integrasi, akan tetapi kemampuan integrasinya dibatasi pada GET data dari setiap sistem yang ada. Menampilkan berita dan pengumuman pada website sekolah ataupun pondok. Menampilkan informasi dari sistem PPDB dan informasi akademik santri.

\subsection{Hasil Perancangan REST API}

Empat tahap dalam perancangan REST API yaitu identifikasi, memahami ekosistem organisasi, mengidentifikasi kemungkinan integrasi dan identifikasi kemampuan integrasi yang diperlukan telah dibahas pada hasil pengumpulan data. Adapun desain arsitektur integrasi sistem di pondok pesanten menggunakan REST API sesuai hasil wawancara sebagaimana pada Gambar 4 berikut. 


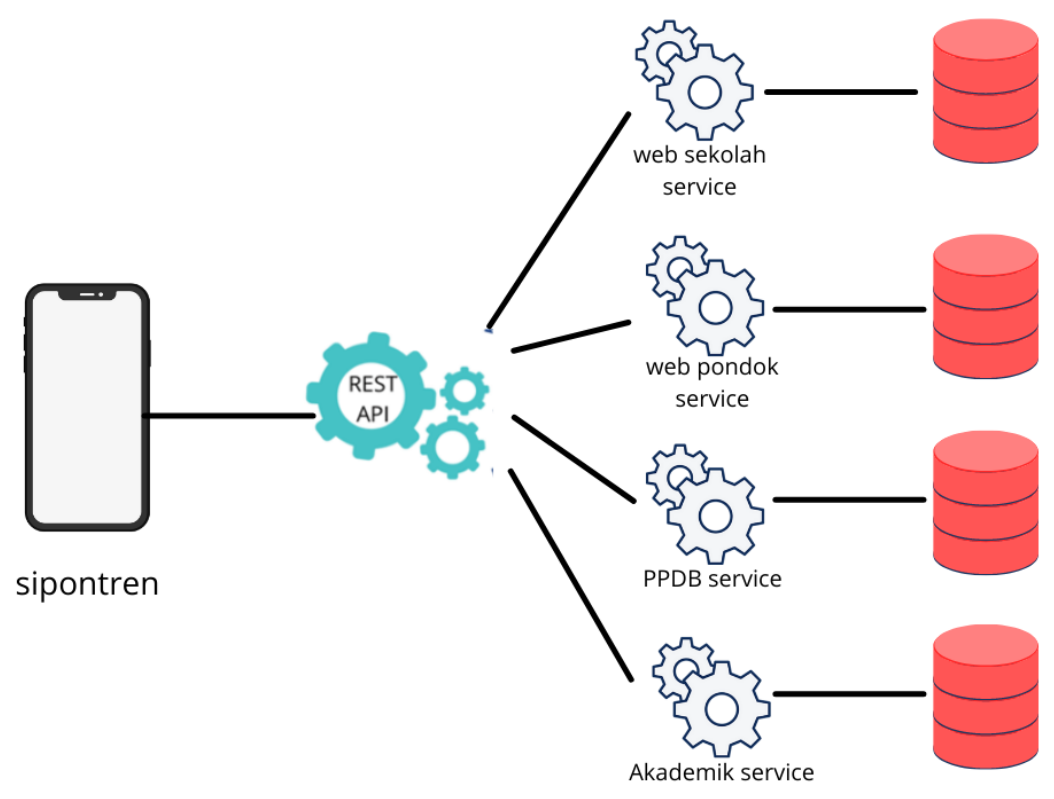

Gambar 4. Desain Arsitektur Integrasi Sistem di Pondok Pesanten

\subsection{Hasil Pengembangan Sistem}

\subsubsection{Hasil Requirement System}

Hasil requirement system dimulai dengan menggambarkan diagram konteks kemudian diagram DFD nya. Gambaran diagram konteks sebagaimana pada Gambar 5.

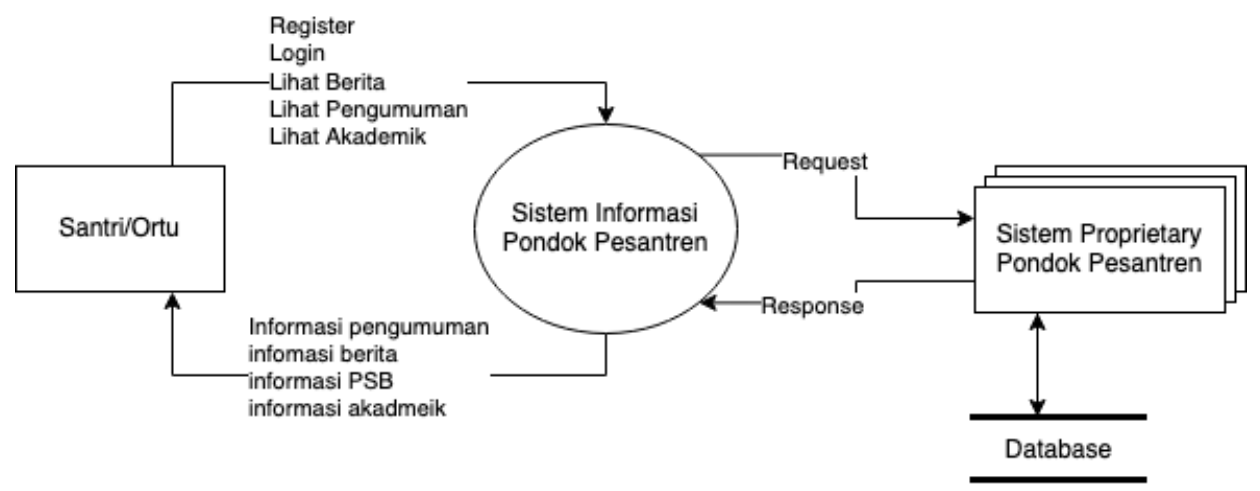

Gambar 5. Diagram Konteks

Pada diagram konteks terdapat dua entitas luar yang berhubungan dengan sistem informasi pondok pesantren terintegrasi yaitu santri/orang tua dan sistem proprietary. Sedangkan gambaran DFD level 0 sebagaimana Gambar 6 menjabarkan aktivitas lebih detail oleh santri/orang tua. 


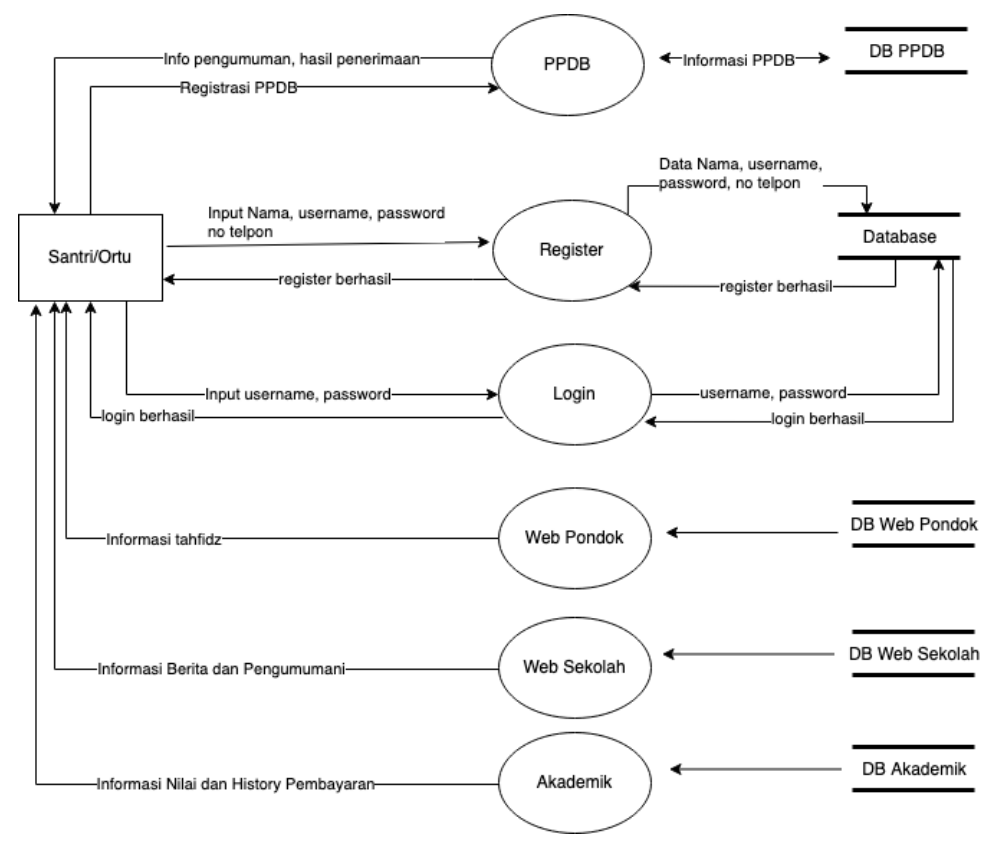

Gambar 6. DFD Level 1

\subsubsection{Hasil Quick Plan and Modeling Quick Design}

Desain antarmuka untuk halaman beranda dirancang terdapat dua bagian utama yaitu informasi pengumuman dan berita terbaru pondok pesantren. Bagian menu berada pada bawah layar menggunakan buttom tabbar. Bagian menu terdiri dari lima menu utama yaitu, home, tahfidz, tugas, akademik dan PPDB. Gambaran desain sistem informasi pondok pesantren terintegrasi berbasis android sebagaimana pada Gambar 7 berikut.

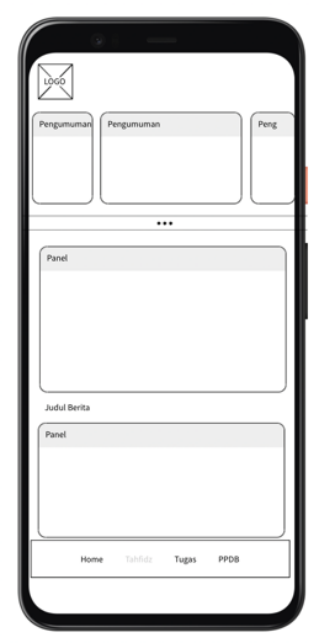

Gambar 7. Desain antarmuka sistem

\subsubsection{Hasil Implementasi dan Pengujian}

Sistem dikembangkan sesuai desain yang telah dirancang. Terdapat beberapa tampilan utama sistem yaitu, halaman utama/home, tahfidz, akademik dan PPDB. Sebagaimana Gambar 8 berikut, sistem telah berhasil mengambil informasi berita terbaru dan pengumuman dari web 
pondok dan sekolah. Hal ini juga termasuk bagian pengujian sistem yaitu menguji keberhasilan fitur/modul dari sistem.

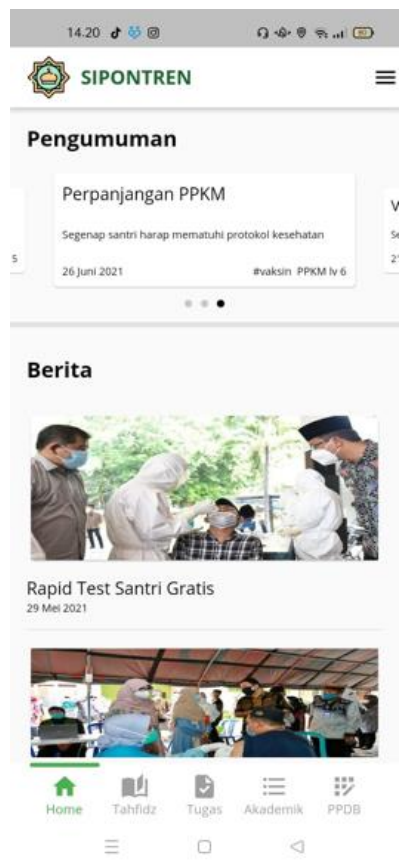

Gambar 8. Halaman Home

Pada menu tahfidz ditampilkan GET data dari web pondok berupa informasi monitoring tahfidz santri. Sebagaimana Gambar 9, data yang ditampilkan berupa diagram dan chart.

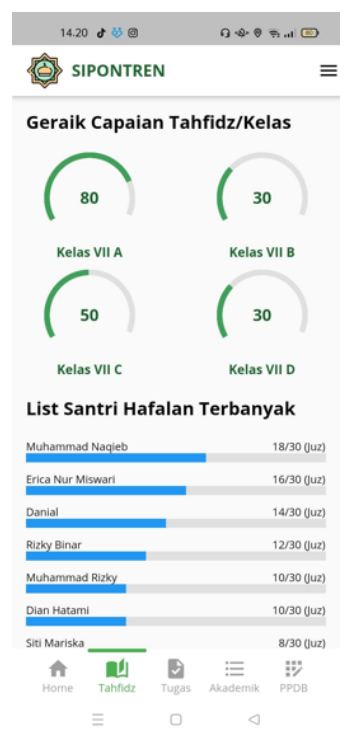

Gambar 9. Halaman Tahfidz

Pada menu akademik, data yang ditampilkan adalah raport dan history pembayaran santri. Pada Gambar 10 didapat dari sistem akademik pondok pesantren. 


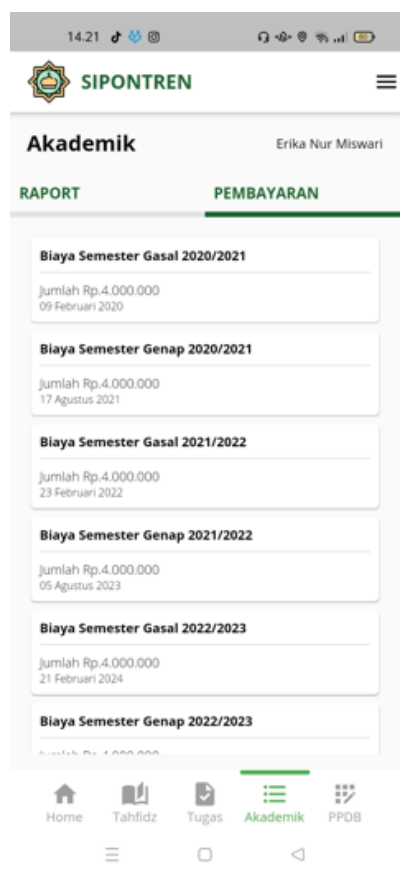

Gambar 10. Halaman Akademik

Pada menu PPDB informasi yang ditampilkan berasal dari sistem PPDB. Informasi yang ditampilkan berupa informasi PPDB, waktu dan tatacara pendaftaran. Tampilan menu PPDB sebagaimana pada Gambar 11 berikut.

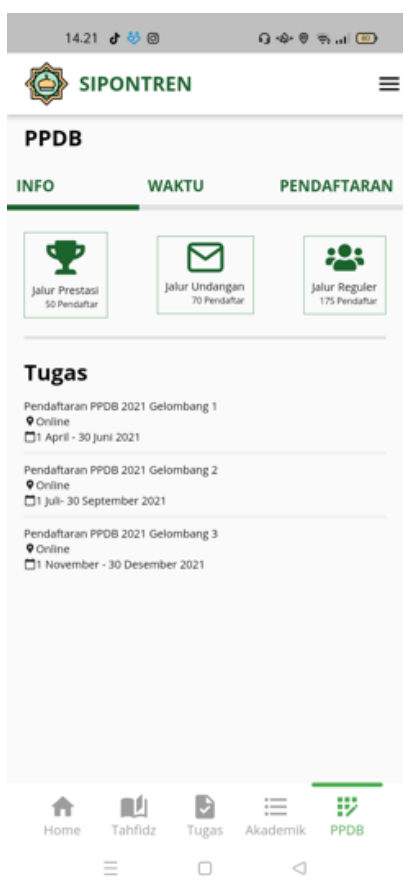

Gambar 11. Halaman PPDB 


\section{Kesimpulan dan Saran}

Sistem informasi pondok pesantren terintegrasi berbasis android merupakan solusi untuk memudahkan santri/orang tua dalam mendapatkan informasi yang tersebar di berbagai sistem. Sistem berhasil mengintegrasikan berbagai sistem yang ada menggunakan metode REST API. Sistem ini menyediakan informasi berita dan pengumuman terbaru, informasi monitoring tahfidz, informasi PPDB dan informasi akademik berupa history pembaran maupun nilai santri.

Saran untuk penelitian selanjutnya adalah bagaimana merancang standar format data untuk pondok pesantren. Semua pondok pesantren memiliki proses bisnis yang sama. Oleh karena itu, dengan merancang format data untuk pondok pesantren, akan memudahkan dalam pengembangan sistem dan integrasi antar pondok pesantren.

\section{Daftar Pustaka}

[1] L. Suryatni, "Teknologi Pendidikan Sebagai Pelaksanaan Sistem Informasi Dalam Perkuliahan Online Di Masa Pandemi Covid-19," JSI (Jurnal Sist. Informasi) Univ. Suryadarma, 2021.

[2] S. Kahfi and R. Kasanova, "Manajemen Pondok Pesantren Di Masa Pandemi Covid-19," Pendek. J. Pendidik. Berkarakter, 2020.

[3] S. A. Prasetia and M. Fahmi, "Reorientasi, Peran dan Tantangan Pendidikan Islam di tengah Pandemi," TARBAWI, vol. 9, no. 1, 2020, doi: 10.36781/tarbawi.v9i1.3128.

[4] T. Wasyik and A. Hamid, 'Implementasi E-Learning dalam Pembelajaran Al-Qur'an Era Covid-19 di Sanggar Tahfidz Enterpreuner Krian Sidoarjo,” Dudeena, vol. 4, no. 1, 2020.

[5] Arifudin, "Implementasi Teknologi Informasi Dan Komunikasi Dalam Kegiatan Pembelajaran Dalam Jaringan (Daring) Pada Pondok Pesantren An Nashuha Kalimukti (Studi Kasus Di Madrasah Aliyah Negeri (Man) 5 Cirebon),” 2020, pp. 40-44.

[6] E. Eliana and M. D. Rahmatya, "Perancangan Sistem Informasi Administrasi Pada Pondok Pesantren Pembangunan Sumur Bandung," J. Teknol. dan Inf., vol. 9, no. 1, pp. 1-11, 2019, doi: 10.34010/jati.v9i1.1330.

[7] R. Kurniadi and J. Devitra, "Analisis Dan Perancangan Sistem Informasi Administrasi Pembayaran Biaya Pendidikan Berbasis Web Dan Sms Gateway Pada Pondok Pesantren Modern Darussalam Mersam," J. Manaj. Sist. Inf., 2020.

[8] F. U. Elly and Fatmasari, "Rancang Bangun Sistem Akademik ( SIAKAD ) Berbasis Web Pada Pesantren Tahfidz Adh Dhuhaa Bulak Santri," J. Sist. Inf. STMIK Antar Bangsa, vol. 9, no. 2, pp. 64-71, 2020.

[9] A. B. Setiawan and J. Sulaksono, "Sistem Informasi Manajemen Santri Di Pondok Pesantren Al Ishlah Kota Kediri," Netw. Eng. Res. Oper., vol. 4, no. 2, pp. 81-86, 2019, doi: 10.21107/nero.v4i2.122.

[10] C. S. Jannah, Erliyah Nurul; Karimah, Inayatul; Anugrah, "Sistem Informasi Manajemen Kegiatan Santri Pondok Pesantren Berbasi Web," Semin. Nas. Teknol. Inf. dan Komun. 2018 (SENTIKA 2018), pp. 260-267, Feb. 2018.

[11] S. M. Marier and P. F. Dewi, "Tahfidz Quran Monitoring System in Islamic Boarding 
Schools," Telematika, 2021, doi: 10.31315/telematika.v18i1.3931.

[12] A. B. Setiawan et al., "Penerapan Sistem Informasi Berbasis Website di Pondok Pesantren Kota Kediri," Gener. J., vol. 3, no. 1, pp. 11-15, 2019.

[13] M. W. R. Fakhrun and S. F. S. Gumilang, "Rancangan Web Service Dengan Metode Rest Api Untuk Integrasi Aplikasi Mobile Dan Website Pada Bank Sampah," Konf. Nas. Sist. Inf., pp. 214-219, 2018.

[14] I. B. P. Manuaba and E. Rudiastini, "API REST Web service and backend system of Lecturer's Assessment Information System on Politeknik Negeri Bali," J. Phys. Conf. Ser., vol. 953, no. 1, 2018, doi: 10.1088/1742-6596/953/1/012069.

[15] N. A. Rakhmawati, S. H. Suryawan, M. A. Furqon, and D. Hermansyah, "Indonesia's Public Application Programming Interface (API)," J. Penelit. Pos dan Inform., vol. 9, no. 2, p. 85, 2019, doi: 10.17933/jppi.2019.090201.

[16] I. O. Suzanti, N. Fitriani, A. Jauhari, and A. Khozaimi, "REST API Implementation on Android Based Monitoring Application,” J. Phys. Conf. Ser., vol. 1569, no. 2, 2020, doi: 10.1088/1742-6596/1569/2/022088.

[17] A. Nanayakkara, "A Seven-Step Guide to API-First Integration," 2020. https://www.infoq.com/articles/api-first-integration/.

[18] R. S. Pressman, Software Engineering A Practitioner's Approach, Seventh Ed. 2010.

[19] F. Soufitri, "Perancangan Data Flow Diagram Untuk Sistem Informasi Sekolah (Studi Kasus Pada Smp Plus Terpadu)," Ready Star, vol. 2, no. 1, pp. 240-246, 2019.

[20] I. C. Society, Guide to the Software Engineering Body of Knowledge Version 3.0 (SWEBOK Guide V3.0). . 